Frontiers in Biomechanics 


\section{Frontiers in Biomechanics}

Edited by

G.W. Schmid-Schönbein

S.L-Y. Woo

B.W. Zweifach

With 136 Figures

Springer-Verlag

New York Berlin Heidelberg Tokyo 
G.W. Schmid-Schönbein Department of Applied Mechanics and Engineering Sciences-Bioengineering, University of California, San Diego, La Jolla, California 92093, U.S.A.

S.L-Y. Woo Department of Surgery, Division of Orthopedics and Rehabilitation, University of California, San Diego, La Jolla, California 92093, U.S.A.

B.W. ZweIFACH Department of Applied Mechanics and Engineering Sciences-Bioengineering, University of California, San Diego, La Jolla, California 92093, U.S.A.

Cover art by Venus K. Sobin. Used with permission.

Library of Congress Cataloging in Publication Data

Main entry under title:

Frontiers in biomechanics.

Bibliography: $p$.

Includes index.

1. Biomechanics-Congresses. 2. Human mechanics-Congresses. 3. Fung, Y.C. I. Fung, Y.C. (Yuan-cheng), 1919- ～. II. Schmid-Schönbein, G.W. III. Woo, Savio L-Y. IV. Zweifach, Benjamin W. (Benjamin William), 1910QP303.F69 $1985 \quad 612^{\prime} .014 \quad 85-17157$

(C) 1986 by Springer-Verlag New York Inc.

Softcover reprint of the hardcover 1st edition 1986

All rights reserved. No part of this book may be translated or reproduced in any form without written permission from Springer-Verlag, 175 Fifth Avenue, New York, New York 10010, U.S.A.

The use of general descriptive names, trade names, trademarks, etc., in this publication, even if the former are not especially identified, is not to be taken as a sign that such names, as understood by the Trade Marks and Merchandise Marks Act, may accordingly be used freely by anyone.

While the advice and information in this book are believed to be true and accurate at the date of going to press, neither the authors nor the editors nor the publisher can accept any legal responsibility for any errors or omissions that may be made. The publisher makes no warranty, express or implied, with respect to the material contained herein.

Typeset by Asco Trade Typesetting Ltd., Hong Kong.

98776544321

ISBN-13: 978-1-4612-9337-8

e-ISBN-13: 978-1-4612-4866-8

DOI 10.1007/978-1-4612-4866-8 


\section{Foreword}

Biomechanics is concerned with the response of living matter to forces, and its study has taken long strides in recent years. In the past two decades, biomechanics has brought improved understanding of normal and pathophysiology of organisms at molecular, cellular, and organ levels; it has helped developing medical diagnostic and treatment procedures; it has guided the design and manufacturing of prosthesis and instruments; it has suggested the means for improving human performance in the workplace, sports, and space; it has made us understand trauma in war and in peace. Looking toward the future, we see many more areas of possible development such as:

- reduction in heart diseases and atherosclerosis

- improved vascular assist and replacement devices, including a permanent artifical heart

- enhanced oxygen transport in the lung

- understanding and control of growth and changes

- mechanics of neuromuscular control and robotics

- prevention of joint degeneration

- permanent total joint replacements

- prevention of low back pain

- workplace designs to enhance productivity

- ambulation systems for the handicapped

- fully implantable hearing aids

- improved understanding of the mechanisms for permanent disability injuries

- identification of factors such as alcohol use and disease influence on impact tolerance

- improved cellular bioreactor designs

- mechanics of DNA and its application in biotechnology.*

Obviously, the attainment of these prospects will greatly improve the quality of human life and reduce the costs of living.

* This list is from a report by the U.S. National Committee on Biomechanics, April, 1985. 
Looking at the frontiers of science is always great fun. This is what this book offers. I derived a tremendous pleasure reading it. Waves of excitement went through me. Again and again the ideas here generated in my mind beautiful vistas of the future and immediate plans for new investigations to be made.

These descriptions of the scenes at the frontiers of biomechanics are stories of considerable accomplishment. Wang Kuo-wei has analyzed the course of any significant accomplishment. He asserts that any person making a significant contribution must have gone through three stages: the stage of seeing the prospects, the stage of hard work and frustration, and the stage of sudden and unexpected success. He culled three stanzas from three famous Chinese poems to describe the moods of these stages, ${ }^{*}$ and Donald Hall and Chia-shun $\mathrm{Yih}^{\dagger}$ translated them into English as follows:

\section{I}

Last night the west wind rising stripped leaves from the green tree.

I climbed alone to the top floor of my house, and looked up the road as far as the horizon.

II

For love of her, I grew pale;

I turned thin and haggard.

For love of her, the belt

hung loose on my robe.

... Yet I regretted nothing.

III

I looked for her in the crowd

a hundred, a thousand times, then suddenly, as I turned

my head, I glimpsed her

in the dim light, in half-darkness.

Every author who has contributed to this book recognizes these moods. Each scientific discipline has its own life cycles, too, and each cycle goes through the stages Wang alluded to. At what stage is biomechanics? I think it is mostly in the first two, and the evidences can be seen in this book. Every chapter

\footnotetext{
* Wang Kuo-wei (1877-1927) was a famous archaeologist, historian, and poet. These remarks were given in his book “On Living Poetry” (王國維, 人間詞話, 開明書店, p. 16). The first stanza is the work of Yen Shu (991-1055, 晏殊, 蝶戀花), the second is the work of Liu Yung (990-1050?, 柳永, 鳳棲梧), and the third is the work of Hsin Chi-hsi (1140-1207, 辛棄疾, 靑玉案).

+ Donald Hall is an American poet. Chia-shun Yih is a fluid dynamicist and mathematician. These translations were read at a banquet in the Hyatt Regency Hotel, Mission Bay, San Diego, on 22 July 1984.
} 
opens up a perspective to a larger field, suggesting many possible applications to engineering, industry, and the health of people and animals. Most of them have not yet arrived at the state of perfection as described by Direchlet of Gauss's work: finished sculpture on which all chisel marks have been polished off. And this is probably good for students, who need the chisel marks to guide them.

This book is written by people I know and to whom I am affectionately attached. It is impossible to describe the deep emotion of the individual who stands at the receiving end of the dedication from them. I thank one and all of them.

Y.C. Fung 


\section{Preface}

Advances in every aspect of scientific knowledge during the past decade have been catalyzed not so much through the development of sophisticated instrumentation, but through the marriage and interaction between hitherto separate basic sciences. Nowhere is this situation better exemplified than with respect to the enormous impact that the application of the tools and methods of applied mechanics has had on the life sciences. The creation of the new discipline of biomechanics has been formalized through the development of new models and constitutive equations. This approach has added new dimensions to applied mechanics in the exploration of structure-function relationships in living materials.

A recent symposium in honor of the 65th birthday of Professor Y.C. Fung was timely not only because it dealt with innovative and provocative aspects of biomechanics, but also because it exemplified the substantial advances made possible by an interdisciplinary approach. This volume, a compendium of the symposium entitled "Frontiers of Applied Mechanics and Biomechanics" held at the University of California, San Diego, in July 1984, covers a spectrum of topics at the core of modern biomechanics research. It is clear that an interdisciplinary approach involves not only the transcription of established methodology from one field to another, but also the formulation of new field equations dealing with the unique properties of biological materials and systems.

In arranging the topics to be included in this volume, primary consideration was given to the suitability of the coverage and contents for graduate student use in biomechanics. A major objective of the book is to provide sufficient background material, terminology, specific formulations, and literature references to guide the reader in further exploration into biomechanics research. No attempt is made to be all-inclusive, but rather to develop representative areas that reflect the contributions of the Fung school of thinking as a basis for the directions in which biomechanics is moving.

The choice of the honoree, Professor Y.C. Fung, was especially propitious, not only because he so uniquely exemplifies the insatiable curiosity and singularity of purpose so necessary for the emergence of biomechanics as a 
distinctive discipline, but also because he has been so instrumental in opening up the field and providing many of the basic analytical tools needed. Interdisciplinary activity requires the strong personal commitment and vision of key individuals whose insight and guidance serve as a catalyst. Y.C. Fung is one of these rare individuals. His impact on the field of biomechanics has been decisive, and his leadership has stimulated students and colleagues to join him in the endeavor of biomechanics. This volume is dedicated to him as a token of the esteem and admiration in which he is held by the entire scientific community. He has made the long road ahead much brighter and smoother.

G.W. Schmid-Schönbein

S.L-Y. Woo

B.W. Zweifach 


\section{Contents}

Part I Molecules and Cells

1. Membrane Mechanics and Cell Adhesion 3 E.A. Evans

2. New Birth To Runaway Solitons 18 T.Y. Wu

3. Leukocyte Protopodia

G.W. Schmid-Schönbein, R. Skalak, S. Chien

\section{Part II Biological Tissues}

4. Biomechanics of Smooth Muscle

J.M. Price

5. Smooth Muscle Rheology: In Search of a Specimen

H.Y.-L. CHeN, E.F. OWENS JR.

6. The Phenomenology of the Heart Muscle

J.G. Pinto

7. Determination of Material Properties of Biological Tissues:

Pericardium

P.H. Chew, S.L. Zeger, F.C.P. YiN

8. In-Vivo Measurement of Regional Strains in Myocardium

L.K. WALDMAN

9. Residual Stress in Arteries

C.J. Chuong, Y.C. Fung 
10. On the Structural Origin of the Quasilinear Viscoelastic Behavior of Tissues

Y. LANIR

11. Fibrous Skin Mechanics: Superstructure and New Problems

S.A. WAINWRIGHT

12. Mechanism of Osmosis: Hulett's Versus Lewis' View of Altered Solvent in Solution

H.T. HAMmEl, A.R. HARGENS

\section{Part III Orthopedics}

13. A Finite Deformation Theory for Nonlinearly Permeable Soft Hydrated Biological Tissues

V.C. Mow, M.K. Kwan, W.M. LaI, M.H. Holmes

14. Biomechanics of Tendons and Ligaments

S.L-Y. Woo

15. Bone Mechanics: From Tissue Mechanical Properties to an Assessment of Structural Behavior

W.C. Hayes

16. Biomechanics of the Lumbar Spine

A.I. KING, K.-H. YANG

17. Biomechanics of the Human Gait

E.Y.S. CHaO

18. Biomechanics of Bone-Implant Interactions

R. HuISKES

19. Mechanics of Healing Soft Tissue Wounds
A. VIIDIK, F. GotTRUP

\section{Part IV Circulation}

20. Biomechanics of the Microcirculation

B.W. ZWEIFACH

21. Biomechanics of Capillary Blood Flow 
22. The Static Versus the Dynamic State of the Microvasculature M. InTAGLIETtA

23. Vascular Dynamics and the Endothelium

R.M. Nerem, M.J. Levesque, M. Sato

24. Self-excited Oscillation of a Collapsible Tube Conveying Fluid

Y. MatsuZaKi

Part V The Lung

25. Microvascular Hematocrit of the Lung

J.S. LEE

26. Pulmonary Blood Flow in the Cat: Correlation Between Theory and Experiment

R.T. Yen, S.S. SobIN

27. Respiratory Dynamics-Computer Simulation

Y. Seguchi, Y.C. Fung, T. IshidA

Index

393 


\section{Contributors}

E.Y.S. Снао Director, Biomechanics Research, The Mayo Clinic, Rochester, Minnesota 55901, U.S.A.

H.Y.-L. Chen School of Engineering Science and Mechanics, Georgia Institute of Technology, Atlanta, Georgia 30332, U.S.A.

P.H. Chew Department of Physiology, The Johns Hopkins Medical Institutions, Baltimore, Maryland 21205, U.S.A.

S. Chien Department of Physiology, College of Physicians and Surgeons, Columbia University, New York, New York 10032, U.S.A.

C.J. Chuong Biomedical Engineering Program, University of Texas at Arlington, Arlington, Texas 76019, U.S.A.

E.A. Evans Department of Pathology, University of British Columbia, Vancover, B.C., V6T 1W5, Canada.

Y.C. Fung Department of Applied Mechanics and Engineering SciencesBioengineering, University of California, San Diego, La Jolla, California 92093, U.S.A.

F. GotTrup Department of Connective Tissue Biology, Institute of Anatomy, University of Aarhus, University Park, DK-800 Aarhus C, Denmark.

H.T. HAMmel Scripps Institute of Oceanography, University of California, San Diego, La Jolla, California 92093, U.S.A.

A.R. HaRgens Department of Surgery, Veteran's Administration Medical Center, La Jolla, California 92037, U.S.A.

W.C. HaYes Department of Orthopedic Surgery, Beth Israel Hospital, Harvard Medical School, Boston, Massachusetts 02215, U.S.A. 
M.H. Holmes Department of Mathematics, Rensselaer Polytechnic Institute, Troy, New York 12181, U.S.A.

R. Huiskes Laboratory of Experimental Orthopedics, Biomechanics Section, University of Nijmegen, 6500 HB Nijmegen, The Netherlands.

M. Intaglietta Department of Applied Mechanics and Engineering Sciences -Bioengineering, University of California, San Diego, La Jolla, California 92093, U.S.A.

T. IsHIDA Department of Systems Engineering, Kobe University, Rokkodai Nada, Kobe 657, Japan.

A.I. KING Biomechanics Research Center, Wayne State University, Detroit, Michigan 48202, U.S.A.

M.K. Kwan Department of Mechanical Engineering, Aeronautical Engineering and Mechanics, Rensselaer Polytechnic Institute, Troy, New York 12181, U.S.A.

W.M. LAI Department of Mechanical Engineering, Aeronautical Engineering and Mechanics, Rensselaer Polytechnic Institute, Troy, New York 12181, U.S.A.

Y. LANIR Department of Biomedical Engineering, Technion-Israel Institute of Technology, Technion City, Haifa 32000, Israel.

J.S. LeE Division of Biomedical Engineering, University of Virginia Medical Center, Charlottesville, Virginia 22908, U.S.A.

M.J. Levesque Physiological Fluid Mechanics Laboratory, Department of Mechanical Engineering, University of Houston, Houston, Texas 77004, U.S.A.

Y. Matsuzaki Department of Aeronautical Engineering, Nagoya University, Chikusa-ku, Nagoya, Japan 464.

V.C. Mow Department of Mechanical Engineering, Aeronautical Engineering and Mechanics, Rensselaer Polytechnic Institute, Troy, New York 12181, U.S.A.

R.M. Nerem Physiological Fluid Mechanics Laboratory, Department of Mechanical Engineering, University of Houston, Houston, Texas 77004, U.S.A.

E.F. Owens JR. School of Engineering Science and Mechanics, Georgia Institute of Technology, Atlanta, Georgia 30332, U.S.A. 
N. ÖZKaYA Bioengineering Institute, Department of Civil Engineering and Engineering Mechanics, Seeley W. Mudd Building, Columbia University, New York, New York 10027, U.S.A.

J.G. Pinto Department of Mechanical Engineering, San Diego State University, San Diego, California 92182, U.S.A.

J.M. PRICE Department of Physiology, University of South Florida, College of Medicine, Tampa, Florida 33612, U.S.A.

M. Sato Physiological Fluid Mechanics Laboratory, Department of Mechanical Engineering, University of Houston, Houston, Texas 77004, U.S.A.

G.W. Schmid-SchÖnbeIN Department of Applied Mechanics and Engineering Sciences-Bioengineering, University of California, San Diego, La Jolla, California 92093, U.S.A.

T.W. Seсомв Department of Physiology, University of Arizona, Tucson, Arizona 85724, U.S.A.

Y. SEGUCHI Department of Systems Engineering, Kobe University, Rokkodai Nada, Kobe 657, Japan.

R. SkalaK Bioengineering Institute, Department of Civil Engineering and Engineering Mechanics, Seeley W. Mudd Building, Columbia University, New York, New York 10027, U.S.A.

S.S. Sobin American Heart Association-Greater Los Angeles Affiliak, Cardiovascular Research Laboratory, University of Southern California, and Los Angeles County, University of Southern California Medical Center, Los Angeles, California 90033, U.S.A.

A. VIIDIK Department of Connective Tissue Biology, Institute of Anatomy, University of Aarhus, DK-800 Aarhus C, Denmark.

S.A. Wainwright Department of Zoology, Duke University, Durham, North Carolina 27706, U.S.A.

L.K. Waldman Department of Medicine, Cardiology, University of California, San Diego, La Jolla, California 92093, U.S.A.

S.L-Y. Woo Department of Surgery, Division of Orthopedics and Rehabilitation, University of California, San Diego, La Jolla, California 92093, U.S.A.

T.Y. Wu Engineering Science Department, California Institute of Technology, Pasadena, California 91125, U.S.A. 
K.-H. YANG Biomechanics Research Center, Wayne State University, Detroit, Michigan 48202, U.S.A.

R.T. YEN Department of Applied Mechanics and Engineering SciencesBioengineering, University of California, San Diego, La Jolla, California 92093, U.S.A.

F.C.P. YIN Department of Medicine, The Johns Hopkins Medical Institutions, Baltimore, Maryland 21205, U.S.A.

S. Zeger Department of Biostatistics, The Johns Hopkins Medical Institutions, Baltimore, Maryland 21205, U.S.A.

B.W. ZweIFaCh Department of Applied Mechanics and Engineering Sciences - Bioengineering, University of California, San Diego, La Jolla, California 92093, U.S.A. 